\title{
Outcome analysis of intercondylar humerus fractures treated by locking compression plates
}

\author{
Singh V', Uikey $S^{2}$, Ganvir $A^{3}$, Maravi DS ${ }^{4}$, Gaur $S^{5}$ \\ ${ }^{1}$ Dr. Vipendra Singh, PG Resident, Department Of Orthopaedics, ${ }^{2}$ Dr. Suresh Uikey, Assistant Professor, Department. \\ Of Orthopaedics, ${ }^{3}$ Dr. Ajit Ganvir, Assistant Professor, Department Of Orthopaedics, ${ }^{4}$ Dr. (Prof.) Deepak S. Maravi \\ Professor, Department Of Orthopaedics, ${ }^{5}$ Prof. Dr. Sanjiv Gaur, Professor, Department Of Orthopaedics. All are \\ affiliated with Gandhi Medical College, Bhopal. MP, India
}

Address for correspondence: Dr Vipendra singh, Email: vipendra.singhkem@gmail.com

\begin{abstract}
Background: Distal humeral fractures are uncommon fractures. They occur in both younger as well as older patients. The complex shape of the elbow joint, the adjacent neurovascular structures, the sparse soft tissue cover combine to make treatment difficult. Previous methods of conservative treatment have caused significant functional impairment. Thus the consensus has shifted towards treatment with open reduction and internal fixation so as to provide stability and early mobilization. Different modalities like $1 / 3^{\text {rd }}$ tubular plate, reconstruction plate, $\mathrm{K}$ wires, double tension band wiring have been tried. The quality of elbow function following the treatment is related to the degree to which the normal anatomic relationships are restored. Materials and Methods: 27 patients of Intercondylar Humerus fractures classified by Riseborough \& Radin system and treated by ORIF by pre-contoured AO Locking compression plates. Clinical and radiological follow-up performed and patients assessed for pain, range of motion, and Mayo elbow performance score. Results: Average follow up was of 6 months. Average age was 37.5 years (18-62 years). Fracture consolidation observed at an average of 12.8 weeks (10-14 weeks). The outcome was excellent or good in 17 patients. 3 patients had infection, 1 case each of ulnar neuropathy, mal-union and myositis ossificans. There were no cases of implant migration, secondary displacement or implant failure. Conclusion: Anatomically pre-shaped distal humerus locking plate system is useful in providing stable fixation for complex distal articular fracture and facilitating early postoperative rehabilitation. The low rate of implant failure in the present study indicates that the technique is promising.
\end{abstract}

Keywords: Elbow joint, Intra-articular fractures, Locking compression plates.

\section{Introduction}

Intercondylar fractures of the distal humerus are uncommon injuries and present the most difficult challenge of fracture of lower end of Humerus. Distal humeral fractures account for $2 \%-6 \%$ of all fractures and about $30 \%$ of all elbow fractures [1]. The complex shape of the elbow joint, the adjacent neurovascular structures, the sparse soft tissue cover combine to make treatment much more difficult. Closed reduction with immobilization, traction and limited internal fixation has caused significant functional impairment with loss of range of movement [2]. Therefore the consensus has shifted towards treating these fractures with open reduction and stable internal fixation. Depending upon

Manuscript received $25^{\text {th }} \mathrm{Feb} 2016$

Reviewed: $8^{\text {th }}$ March 2016

Author Corrected: $15^{\text {th }}$ March 2016

Accepted for Publication: $26^{\text {th }}$ March 2016 the comminution and displacement, different methods of open reduction and internal fixation like $1 / 3^{\text {rd }}$ tubular plate, reconstruction plate, $\mathrm{K}$ wires, double tension band wiring either individually or in combination have been tried. Two column plates at $90^{\circ}$ to one another in complicated elbow fracture have become standard treatment against which all other treatment methods are measured [3].

There are 2 crucial factors influencing prognosis. The first one is delay in surgical fixation following injury and the second is difficulty in obtaining adequate surgical exposure. Therefore proper surgical approach and timing are important factors for obtaining good functional results. In case of a complex fracture with fragmentation of the articular surface in the sagittal and 
coronal planes and poor bone quality, which render the fracture unamenable to internal fixation, Total elbow arthroplasty (TEA) can be performed; however the functional limitations and eventual failure with arthroplasty must always be kept in mind.
Objectives: There are several methods of treating fractures of the distal humerus. In this study, we treated intercondylar distal humerus fractures using a posterior approach and locking plate fixation and assess the outcomes.

\section{Materials \& Methods}

This prospective study comprised 27 patients with intercondylar fractures of the distal humerus. All underwent bilateral plate fixation. Patients of age 18-65 years and of either sex were included in this study. Exclusion criteria included pathological fracture, previously operated or non functional elbow and open fractures. All fractures were classified on the basis of Riseborough \& Radin classification [4]. After detailed clinical-radiological examination and informed consent, all patients were subjected to surgery under pneumatic tourniquet.

Patients were operated in a lateral position through Campbell's posterior approach. The ulnar nerve was identified and mobilized to prevent iatrogenic damage. Dissection was performed along the triceps brachii muscle bilaterally to the proximal ulna; and osteotomy was performed $2 \mathrm{~cm}$ distal to the tip of the olecranon. The proximal part of the olecranon and its attached triceps tendon were retracted proximally to expose the distal humerus. The distal humerus and elbow were exposed entirely; the intercondylar fracture was first reduced and temporarily fixed by using K-wire to restore the articular surface. Then $4 \mathrm{~mm}$ cannulated screws were inserted to fix the condyles thus reconstructing the articular surface. After reconstruction of the articular surface, the medial and lateral columns were reduced and provisionally fixed to the metaphysis with crossed $2 \mathrm{~mm} \mathrm{~K}$ wires. Then both the columns were reconstructed using $3.5 \mathrm{~mm}$ Precontoured distal humerus locking compression plate (LCP) and screws. Plates were applied at $90^{\circ}$ to each other (Orthogonal plating). At the end of the procedure, reconstruction of the soft tissues was performed. The olecranon was then reduced and fixed by K-wire and tension band wire. The medial portion of the triceps was brought back to the olecranon and the ulnar nerve was seen to fall into its anatomical position. Reattachment of the triceps to the olecranon allowed adjustment of soft-tissue tension. Wound was closed in layers over a negative suction drain. Wound sealed with adhesive dressing and limb immobilized in plaster of Paris above elbow slab with elbow in 90 degree flexion \& mid-prone position.

Patient started on antibiotics and analgesics in immediate post operative period. Intravenous antibiotics were given for 5 days. Limb was elevated and patients were advised to keep moving the fingers and shoulder joint. Hand grip strength exercises were also begun.
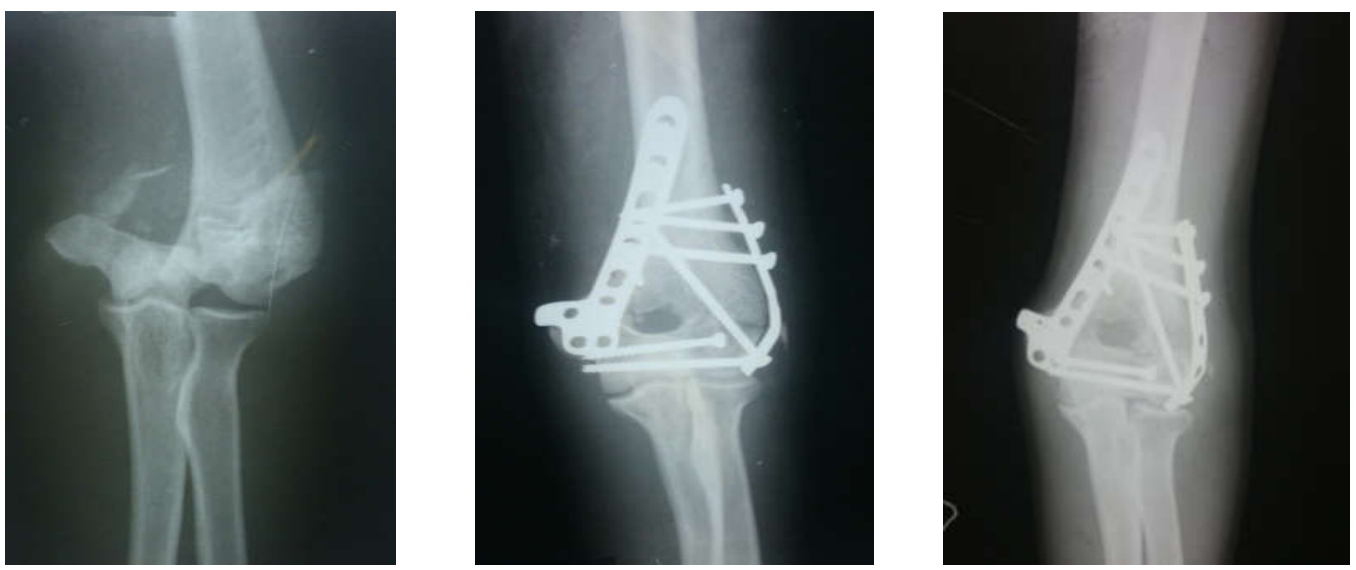

Fig. 1 Pre operative and Post operative $X$ ray and $X$ ray showing union at final follow up

Wound inspected at $3^{\text {rd }}$ post operative day, check dress done and suction drain was removed. Further dressings performed at $5^{\text {th }}$ and $8^{\text {th }}$ post operative day. Suture/ staples were removed on $11^{\text {th }}$ post operative day. 3 weeks after the operation, follow-up took place every 6 weeks until fracture healing occurred. Final follow-up was performed approximately 1 year 
later. These patients were assessed retrospectively by clinical evaluation, exploration of x-rays based on the Riseborough \& Radin classification [4] and functional outcome based on Mayo Elbow Performance Score [5].
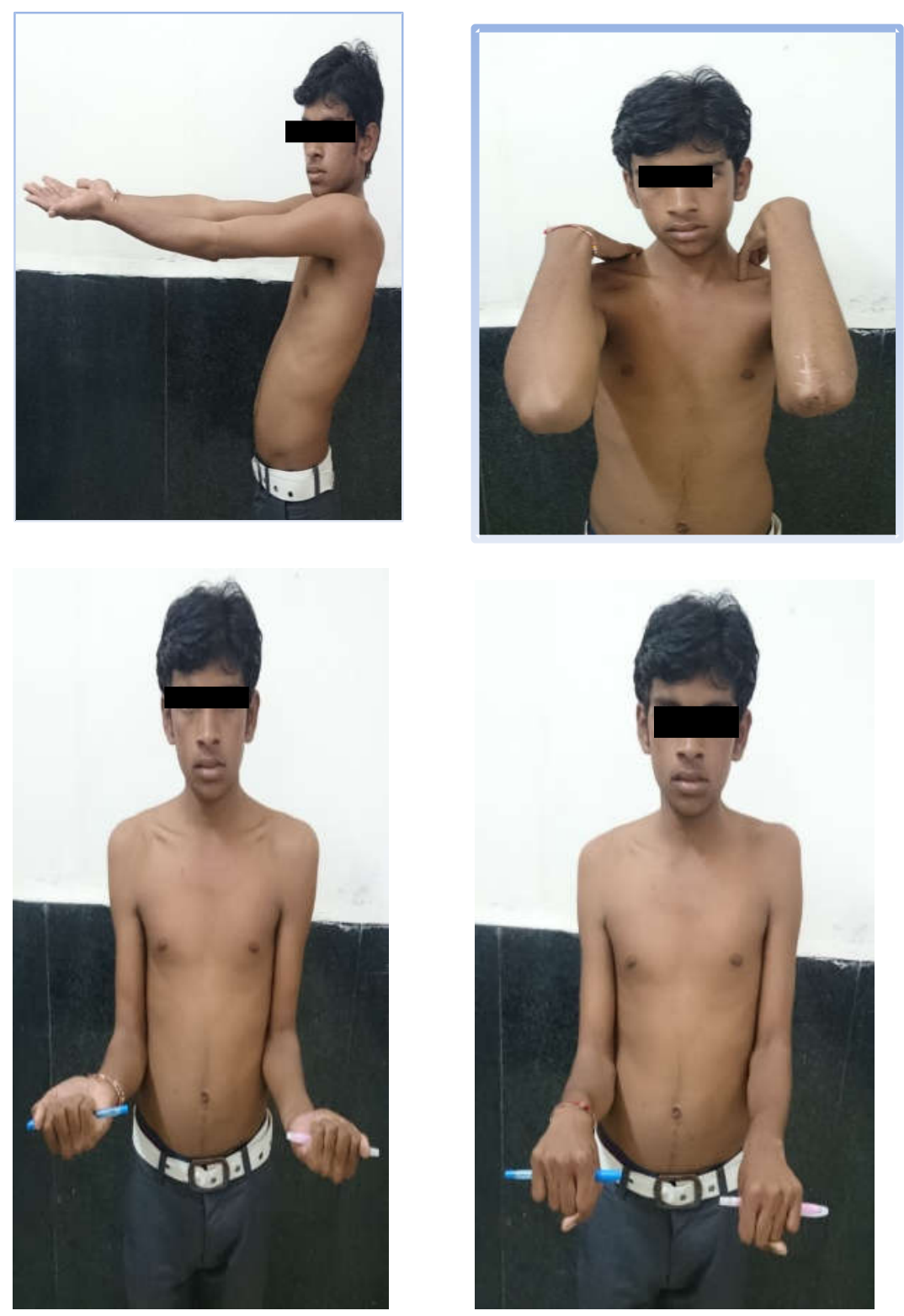

Fig. 2 Clinical photographs showing good range of Flexion - Extension \& Pronation - Supination movements.

\section{Results}

Total 27 patients were available for final follow up and analysis. There were 17 males and 10 female patients. The mean age was 37.5 years, ranging from 18 to 62 years. Majority of cases were due to Road Traffic Accidents (16 cases) as compared to fall (11 cases).

Right elbow was injured in 11 patients as compared to Left elbow which was injured in 16 patients. 4 patients had other associated fractures which included 1 distal radial fracture, 1 radial shaft fracture, 1 fracture of the contralateral clavicle and 1 patient with fracture of the ribs.

Average delay in surgery from the time of injury was about 7 days which was mainly due to delay in reporting to the hospital. According to Riseborough \& Radin classification, there were 2 cases of type I, 8 
cases of type II, 14 cases of type III and 3 cases of type IV fracture. Clinical-radiological consolidation of the fracture was observed in all cases at an average of 12.8 weeks (9-16 weeks). Outcome evaluation done by Mayo Elbow Performance Score (MEPS)[5]. Excellent results were obtained in 4 patients, Good results in 13 patients, Fair in 7 and Poor in 3 patients.

21 out of 27 patients had no complications. There were 3 cases in which infection developed, out of which 2 had superficial infection and 1 had deep infection. 1 case developed Ulnar neuropathy, 1 patient had Malunion and there was 1 case of post operative Heterotopic Ossification.

\section{Discussion}

Distal humeral fractures are difficult management problems on account of the complex anatomy of the elbow, small sized fracture fragments and the limited amount of subchondral bone [6].

Previous treatment methods of closed reduction with immobilization, traction and limited internal fixation have caused significant functional impairment with loss of range of movement. Hence, it is now generally accepted that the most favourable outcome of displaced intraarticular fractures is provided by surgical reconstruction [7]. Different approaches have been described for type $\mathrm{C}$ distal humerus fracture repair [8, 9]. The posterior approach has been used by many surgeons because it exposes the articular surface of the distal humerus sufficiently $[10,11]$.

In this study, we used Locking Compression Plates to reconstruct both the medial and lateral columns as the locking plates provide a fixed plate screw construct with multiple screw options for easy application in distal complex fractures thereby providing angular stability. There is no consensus that whether the orthogonal or parallel plating is superior for fixation [12]. We used orthogonal plating because it provides better mechanical stability although it requires more extensive soft tissue dissection.

In our series, most of the patients were operated by trans-olecranon approach by doing an osteotomy, except in minimally displaced fractures in whom Paratricipital approach was used. The mean delay in surgery in the present study was 7.33 days which was slightly higher than in the studies reported by Muzaffar et al (3.8 days) [13] and Atalar et al (6 days) [14]. This higher injury - surgery interval can be attributed to the delay in reporting to the hospital by the patients.

The average time to union in our study was 12.8 weeks (10-16 weeks) which was same as reported by Pankaj et al (12.8 weeks) [15]. It was less than in study reported by Kumar et al (13 weeks) [16] \& Georgiades et al (16 weeks) [17] although greater than time taken in study by Ali et al (9.6 weeks) [18] and Lakhey et al (12 weeks) [19]. The mean MEPS in the present study were 79 with $63 \%$ (17 patients) achieving excellent to good outcome. Best functional outcome was achieved with Type I fracture.

The complication rate in this study was $22.23 \%$ with 3 cases of infection out of which 1 was superficial infection which was controlled with antibiotics and 2 had deep infection requiring implant removal. Rate of heterotopic ossification was in this study was 3.7\% which is well below the rate in study by Gupta et al (10\%) [20], Gofton et al (13\%) [21] and Kundel et al (49\%) [22].

There was 1 case $(3.7 \%)$ of post - operative ulnar neuropathy which was again lower than the rate reported by Helfet et al (7\%) [23], Reising et al (12.5\%) [24] and much less than $33.7 \%$ rate reported by Kundel et al. There was 1 case of malunion. There was no case of implant failure, screw cut out, implant migration or non-union.

\section{Conclusion}

The results of present series are comparable with other series showing that locking compression plate is a versatile implant providing stable-enough fixation and helping restoration of normal anatomy for good result and early rehabilitation and hence it can be concluded that Locking plate system is a useful option in Intercondylar humerus fractures especially with comminuted small distal fragments, although larger control studies with long term follow-up will be required before advocating it for wider application.

Funding: Nil

Conflict of interest: None.

Permission of IRB: Yes 


\section{References}

1. Robinson CM, Hill RM, Jacobs N, Dall G, CourtBrown CM. Adult distal humeral metaphyseal fractures: epidemiology and results of treatment. J Orthop Trauma. 2003 Jan;17(1):38-47. Adult distal humeral metaphyseal fr

2. Charnley J. The Closed Treatment of Common Fractures. 3rd ed. Baltimore: Williams \& Wilkins; 1961.

3. Self J, Viegas SF, Buford WL Jr, Patterson RM. A comparison of double-plate fixation methods for complex distal humerus fractures. J Shoulder Elbow Surg. 1995 Jan-Feb;4(1 Pt 1):10-6.

4. Riseborough EJ, Radin EL. Intercondylar T fractures of the humerus in the adult. A comparison of operative and non-operative treatment in twenty-nine cases. J Bone Joint Surg Am. 1969 Jan;51(1):130-41.

5. Morrey BF, Adams RA. Semiconstrained arthroplasty for the treatment of rheumatoid arthritis of the elbow. J Bone Joint Surg Am. 1992 Apr;74(4):47990 .

6. Gupta R, Khanchandani P. Intercondylar fractures of the distal humerus in adults:

a critical analysis of 55 cases.

Injury. 2002

Jul;33(6):511-5.

7. Jupiter JB, Mehne DK. Fractures of the distal humerus. Orthopedics. 1992 Jul;15(7):825-33.

8. Wei W, Zhang T, Xin J. The treatment and its results of type C fractures of distal humerus. Chin J Orthop. 2005;25(11):679.

9. Yang KH, Park HW, Park SJ, Jung SH. Lateral Jplate fixation in comminuted intercondylar fracture of the humerus. Arch Orthop Trauma Surg. 2003 Jun;123(5):234-8. Epub 2003 Apr 25.

10. Zhao J, Wang X, Zhang Q. Surgical treatment of comminuted intra-articular fractures of the distal humerus with double tension band osteosynthesis. Orthopedics. 2000 May;23(5):449-52.

11. Athwal GS, Rispoli DM, Steinmann SP. The anconeus flap transolecranon approach to the distal humerus. J Orthop Trauma. 2006 Apr;20(4):282-5.

12. Jacobson SR, Glisson RR, Urbaniak JR. Comparison of distal humerus fracture fixation: a biomechanical study. J South Orthop Assoc. 1997 Winter;6(4):241-9.

13. Muzaffar N, Bhat K, Ahmad R, Wani R, Dar M. Functional results after osteosynthesis of distal humeral fractures with pre-contoured LCP system. Ortop Traumatol Rehabil. 2014 Jul-Aug;16(4):381-5. doi: $10.5604 / 15093492.1119615$.

14. Atalar AC, Demirhan M, Salduz A, Kiliçoğlu O, Seyahi A. [Functional results of the parallel-plate technique for complex distal humerus fractures]. Acta Orthop Traumatol Turc. 2009 Jan-Feb;43(1):21-7. doi: 10.3944/AOTT.2009.021.

15. Pankaj A, Mallinath $G$, Malhotra R, Bhan $S$. Surgical management of intercondylar fractures of the humerus using triceps reflecting anconeus pedicle (TRAP) approach. Indian J Orthop. 2007 Jul;41(3):21923. doi: 10.4103/0019-5413.33686.

16. Kumar MN, Ravishankar MR, Manur R Single locking compression plate fixation of extra-articular distal humeral fractures. J Orthopaed Traumatol (2015) 16:99-104.

17. Georgiades Ch, Matějka J, Pavelka T, Houček P. [Treatment of distal humeral fractures by open reduction and internal LCP-DHP fixation]. Acta Chir Orthop Traumatol Cech. 2010;77(6):479-83.

18. Ali AM, Hassanin EY, El-Ganainy AE, Abd-Elmola T. Management of intercondylar fractures of the humerus using the extensor mechanismsparing paratricipitalposterior approach. Acta Orthop Belg. 2008 Dec;74(6):747-52.

19. Lakhey S, Sharma S, Pradhan RL, Pandey BK, Manandhar RR, Rijal KP. Osteosynthesis of intercondylar humerus fracture using Bryan and Morrey approach. Kathmandu Univ Med J (KUMJ). 2010 AprJun;8(30):154-7.

20. Gupta RK, Gupta V, Marak DR. Locking plates in distal humerus fractures: study of 43 patients. Chin J Traumatol. 2013;16(4):207-11.

21. Gofton WT, Macdermid JC, Patterson SD, Faber KJ, King GJ. Functional outcome of AO type C distal humeral fractures. J Hand Surg Am. 2003 Mar;28(2):294-308.

22. Kundel K, Braun W, Wieberneit J, Rüter A. Intraarticular distal humerus fractures. Factors affecting 
functional outcome. Clin Orthop Relat Res. 1996 Nov;(332):200-8.

23. Helfet DL, Schmeling GJ. Bicondylar intraarticular fractures of the distal humerus in adults. Clin Orthop Relat Res. 1993 Jul;(292):26-36.

24. Reising K, Hauschild O, Strohm PC, Suedkamp NP. Stabilisation of articular fractures of the distal humerus: early experience with a novel perpendicular platesystem. Injury. 2009 Jun;40(6):611-7. doi: 10.1016/j.injury.2008.12.018. Epub 2009 Apr 19.

25. Flinkkilä T, Toimela J, Sirniö K, Leppilahti J. Results of parallel plate fixation of comminuted intraarticular distal humeral fractures. J Shoulder Elbow Surg. $2014 \quad$ May;23(5):701-7. doi: 10.1016/j.jse.2014.01.017.

\section{How to cite this article?}

Singh V, Uikey S, Ganvir A, Maravi DS, Gaur S. Outcome analysis of intercondylar humerus fractures treated by locking compression plates. Int $J$ Med Res Rev 2016;4(3):414-419. doi: 10.17511/ijmrr.2016.i03.23 